\title{
PREPARING STUDENTS FOR THE GLOBAL WORKPLACE: CLASSROOM STRATEGIES FOR DEVELOPING ENGLISH AND INTERCULTURAL COMMUNICATION SKILLS
}

\author{
Anabela Simões \\ ESTGA - Águeda School of Technology and Management \& CLLC - Languages, Literatures \\ and Cultures Research Centre, University of Aveiro (PORTUGAL)
}

\begin{abstract}
According to recent OECD estimates, one-third of all jobs worldwide are likely to be transformed by technology in the next decade [1]. This new reality calls for a reskilling effort, which to be meaningful requires individuals in general, and Higher Education Institutions in particular, to adjust and focus on the fastest-growing professions of the future. From engineering, cloud computing, data and Al to sales marketing and project management, as well as people and culture-related positions - these are some of the professional areas that will soon be most sought after.
\end{abstract}

Another World Economic Forum study [2] points at the fact that, with the inevitable rise of automation, there is a particular set of skills that is now more important than ever: the so-called social or soft skills. Therefore, when it comes to career planning, the ability to communicate and work with others, solve problems, be creative, as well as demonstrate emotional intelligence are all skills that should be perceived as the most important foundation to build upon.

As the modern workplace becomes more global and interconnected, the command of foreign languages plays an ever more important role in international business relations [3]. Simultaneously, it is also vital to know how to navigate the different identities present within culturally diverse environments [4] [5]. As language in itself is not sufficient for effective communication in such contexts, it is also important to grasp how international stakeholders think, work, and express themselves through their attitudes and behaviours [6] [7]. From this understanding of the "other" comes empathy - which is another relevant soft skill in these challenging times.

This paper aims to describe the project 'Building Intercultural Bridges in the Classroom', whose first activity was developed within the English Language and Business Communication course, held at the Águeda School of Technology and Management of the University of Aveiro, during the first semester of the academic year 2019/2020.

Literature demonstrates that student-centred learning environments, where practical and more realistic assignments can be developed, are likely to be more effective and conducive to a greater level of development of both technical and interpersonal skills [8]. With this premise in mind, the proposed activities, which were built upon the interaction of ELBC students with international volunteers from the European Solidarity Corps, seek to involve students more actively in the development of their English communication skills, as well as of their intercultural competences and other relevant technical and soft skills.

In addition to the detailed description of the project, this paper also aims to present the results of a survey on students' perception of the carried out activities. The gathered data indicates that students perceived the proposed tasks as highly rewarding and that both technical and interpersonal competencies were successfully addressed.

Keywords: language teaching strategies, English for specific purposes, business communication, communicative competence, intercultural sensitivity.

\section{INTRODUCTION}

Tell me and I forget, teach me and I may remember, involve me and I learn.

Benjamin Franklin

With one-third of all jobs worldwide likely to be transformed by technology in the next decade [1], we are all living a technological revolution that is changing the way we live, work, and relate to one another to a degree humankind has never experienced before. This reality calls for a response that 
must be integrated and comprehensive, one that involves all stakeholders of the global polity, from the public and private sectors to civil society and higher education institutions (HEI) [9].

Fully aware of industry expectations regarding the need for 'work-ready' graduates, HEls are already playing their part in the process [10]. In fact, major changes have taken place in European Higher Education over the past years. One of the most significant developments is the shift in the learning paradigm: the evolution from traditional, teacher-centred instructional models to learner-centred approaches, which, according to several studies, tend to be more effective and conducive to a higher competence development [8].

Competence, which the European Commission defines as "the proven ability to use knowledge, skills and personal, social and/or methodological abilities, in work or study situations and professional and personal development" [11], can be divided into two distinct categories: the cognitive and technical competences, also commonly known as 'hard skills', and those of a transversal nature, coined as 'soft skills'. As illustrated in Fig.1, whereas hard skills refer to easily defined and measured knowledge or abilities that are obtained through (certified) schooling, training, courses and on-the-job training, soft skills - which are often transferable across careers and industries - refer to any skill or quality that can be classified as a personality trait or habit. Communication skills and interpersonal skills (face-to-face exchange of thoughts, ideas, feelings and emotions, including both verbal and nonverbal elements of personal interaction) are more specific categories of soft skills that many employers seek in job candidates [12].

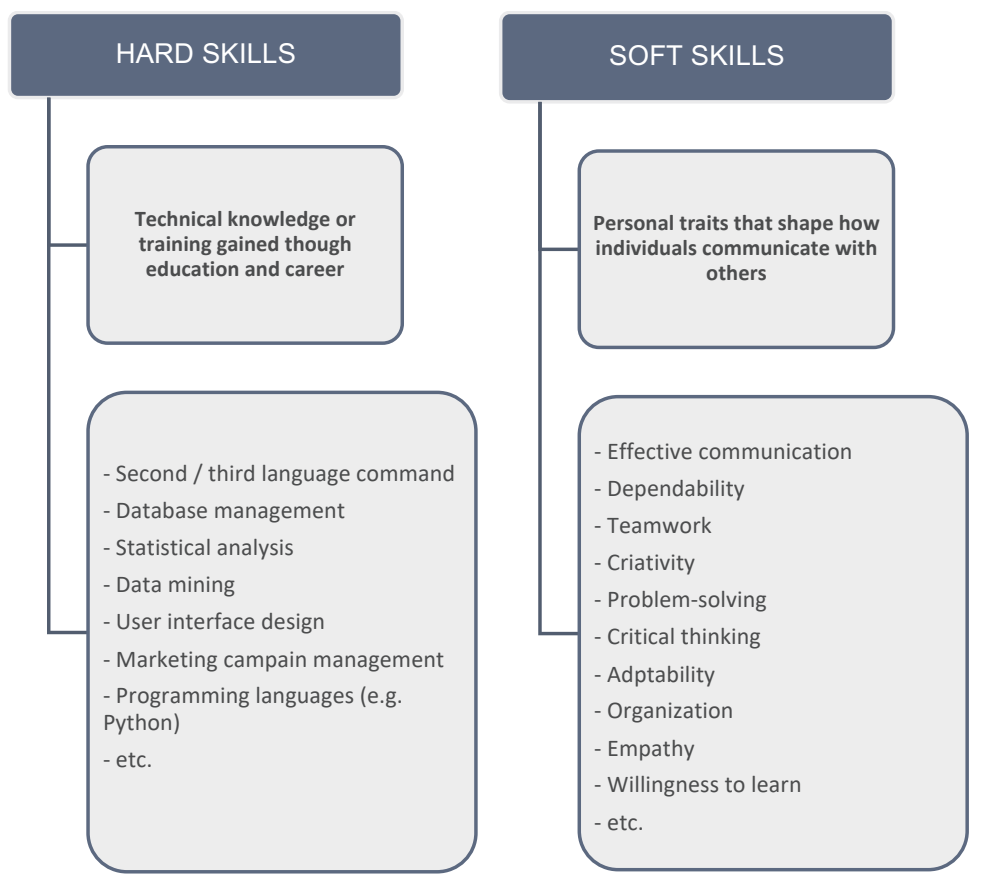

Figure 1. Hard skills vs soft skills.

Source: Own elaboration, based on [12].

The new reality brought by the Fourth Industrial Revolution calls for a reskilling effort, which to be meaningful requires individuals in general, and HEls in particular, to adjust and focus on the fastestgrowing professions of the future. Alongside engineering, cloud computing, data and $\mathrm{Al}-$ all obvious examples of professional areas that will soon be most sought after - people and culture-related positions will be equally crucial [1]. This means that, despite the inevitable rise of automation, there is a particular set of skills that is now more important than ever: the so-called social or soft skills [2]. Therefore, when it comes to career planning, the ability to communicate and work with others, solve problems, be creative, as well as demonstrate emotional intelligence are all competencies that should be perceived as the most important foundation to build upon.

As the modern workplace becomes more global and interconnected, employers are also seeking 'global-ready' graduates [13], that is, individuals competent in communicating with people from different cultural backgrounds. Due to its strategic importance, the command of a second/third language is, therefore, an ever more valuable asset. With its over 1.5 billion speakers worldwide [14], 
English occupies a central position in this process; it has become not only the language of science and technology [15] but also the global language of business. According to [16], more and more multinational companies are defining English as their common corporate language to facilitate communication and performance across geographically diverse functions and business ventures.

With the current corporate trend towards globalization and internationalisation, not only language competence but also grasping how international stakeholders think, work, and express themselves through their attitudes and behaviours has gained added importance [6] [7]. Because cultural differences can indeed affect the efficiency of processes and the development of a business, it is, therefore, critical to help students develop an intercultural mindset, one that allows the individual to navigate effectively across different cultural settings [4] [5]. According to [4], awareness of how cultural differences can affect business communication is not just helpful, it's essential; organisations that understand and accommodate individuals from different cultural backgrounds are better equipped to scale and build a better reputation amongst such a competitive global market.

The development of key competences, including intercultural communication competence (ICC), is one of the main goals of HEls. As [17] explains, intercultural communication (IC) refers to "the ability to communicate efficiently and appropriately in intercultural situations based on one's cross-cultural knowledge, skills, and attitudes". ICC can also be defined as "an individual's ability to achieve their communication goal while effectively and appropriately utilizing communication behaviors to negotiate between the different identities present within a culturally diverse environment" [6]. ICC is comprised of three dimensions: i) intercultural awareness, ii) intercultural sensitivity, iii) and intercultural effectiveness [18], each one associated with a specific feature of the Self (Fig. 2).

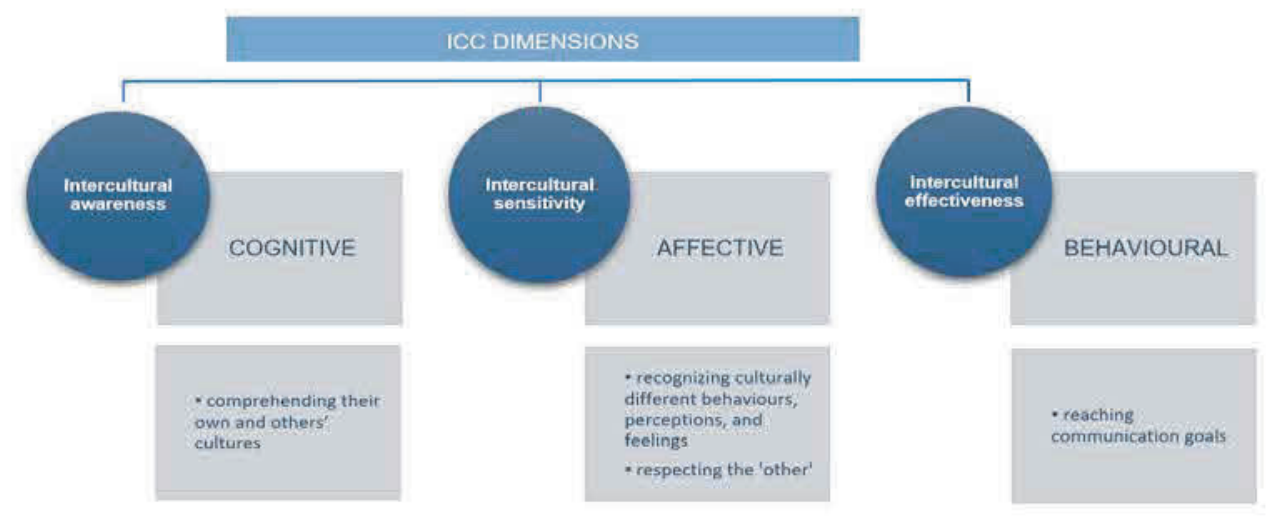

Figure 2. Dimensions of intercultural communication competence (ICC). Source: Own elaboration, based on [19].

In its nature, intercultural awareness is a cognitive process through which an individual knows and understands cultural characteristics and traditions that influence people's behaviours and consciousness. On the other hand, intercultural sensitivity, which refers to the ability to develop a positive attitude towards cultural differences, represents the affective aspect of IC. Finally, intercultural effectiveness refers to the actual behaviour of an individual, when they are able to act effectively and reach their communication goals in a cross-cultural setting [19] [20].

The objective of the present paper is to present a student-centred activity that was based upon the articulation of a research assignment and an oral presentation, then followed by an interaction moment between students and peers from different cultural backgrounds. On the one hand, and considering the broad skillset it requires, conducting research is not only an important component for the development of scientific thinking but also a very relevant skill in any business-related context [21] [22]. On the other hand, the proposed activities sought to integrate knowing and doing while developing important soft skills such as organisation, cooperation and sense of agency and responsibility, as well as students' overall and intercultural communication skills. Finally, by analysing students' perceptions this paper also aims at assessing the effectiveness of the pedagogical activity. 


\section{CONTEXT}

The undergraduate academic degree in Office Management and Business Communication (OMBC), awarded by the Águeda Higher School of Technology and Management of the University of Aveiro (ESTGA-UA), aims at training qualified professionals capable of assisting and providing support to board or administrations members of public and private companies or agencies, at both national and international levels. Since its adaptation to the Bologna Process principles and objectives, in academic year 2007/2008, the course structure of this six-semester degree (180 ECTS) covers different disciplinary areas such as Languages, Secretarial Studies and Business Communication, Social Sciences, Information Technology, among others. Due to its multi- and interdisciplinary training, graduates are prepared to manage complex communication flows, contributing thus to the management process and development of organisations.

Aware of the importance of mastering foreign languages in an ever more global and competitive labour market, the study programme in OMBC includes nine 60-hour foreign language (FL) courses five courses of English (mandatory) and four courses of a second FL (in their first semester students can opt for French or German). Moreover, in their sixth semester, students have the opportunity to complete an internship in an organisation; during this period, business writing and oral interactions with different stakeholders in one or two of the learned FL are also frequent activities integrated into students' work plans.

The below described formative activity took place within the upper intermediate level course English Language and Business Communication (ELBC). Directed to $3^{\text {rd }}$-semester students, ELBC aims, on the one hand, at consolidating and improving previously acquired language skills, and, on the other hand, at promoting activities that are consistent with students' future professional needs. By the end of the course, which is built around four main sections - 1. Communication; 2. Intercultural communication; 3. Intercultural sensitivity in business communication; 4. Business communication: telephoning and socializing (in general and in cross-cultural contexts) -, students are expected to:

- describe various types of communication and recognise the contextual variation of the language;

- produce oral and written texts, consistent and appropriate to different contexts of business communication;

- identify dysfunctional communicative situations in intercultural contexts;

- develop research in the field of intercultural communication;

- present and critically analyse the results of this research;

- optimise the production of oral and written statements in a business context through the use of online tools.

Through its Youth Center Office, the city of Águeda has been the host location of volunteers from the European Solidarity Corps (ESC) - a European Union initiative that aims at creating opportunities for young people to volunteer or work in projects in their own country or abroad that benefit communities and people around Europe. European Solidarity Corps projects, which are available to participants over 18 up to the age of 30 years old, may include the prevention of disasters or and/or subsequent rebuild, assisting in centres for asylum seekers, or addressing different social issues in communities [23].

In 2019/2020 the Águeda Youth Center, which is one of ESTGA-UA's local partner entities, welcomed volunteers from seven countries: Austria, England, Spain, Finland, Germany, Greece and the Republic of North Macedonia. Already attending Portuguese lessons at ESTGA-UA and being acquainted with some Portuguese students created an excellent opportunity to invite volunteers into class and organise an intercultural activity where some of the conceptual aspects studied within ELBC could be linked to real testimonials. This intercultural encounter, which took place on the $12^{\text {th }}$ December 2019 , marks the beginning of the pilot project 'Building Intercultural Bridges in the Classroom', an initiative that aims at involving students in the development of their linguistic and intercultural skills in more active and motivating ways, such as the direct contact with peers from different geographies. 


\section{PRESENTATION OF THE ACTIVITY}

One month prior to the event, the 19 students enrolled in ELBC were challenged to organise themselves in three groups and prepare a presentation of their country and the main traits of their culture to the ESC volunteers. To help students focus their attention on specific aspects, each group was given a list of relevant topics to research. Table 1 summarises the guidelines given to each group. The theoretical framework that supports topics 1.4. and 1.5. - Geert Hofstede's cultural dimensions model and Edward Hall's high and low-context cultural framework - is part of the course syllabus and was, therefore, extensively discussed in class.

Above all, the main focus was not so much the information or aspects that are easily seen/found by non-natives, i.e. the explicit manifestations of students' national culture, rather reflect upon their own thought patterns and underlying beliefs, attitudes and behaviours, that is to say, all those specific traits that are implicit, or - to use the cultural iceberg metaphor - those characteristics that are underneath the surface [24] and, therefore, out of conscious awareness. When interacting/working across cultures it is precisely this deeper level of culture that leads to difficulties or communication problems that intercultural training seeks to help overcome.

Moreover, to enrich our visitors' experience, a group of $5^{\text {th }}$-semester students were also invited to participate and present the information displayed on topic 4 (which resulted from a class assignment developed within the course English Language and Organizational Culture).

During the preparatory stage of the activity, additional support and feedback on the on-going work were provided by the teacher.

Table 1. Profiling Portugal: list of suggested/targeted topics

\section{GROUP 1. Country's presentation}

1.1. General info, geographic and demographic data

1.2. National symbols

1.3. Celebrations / Festivities

1.4. Country analysis through Hofstede's 6-D model

1.5. Allocation to Hall's high- / low-context cultures

\section{GROUP 2. Communication made easy}

2.1. Gestures and other nonverbal communication

2.2. Idioms

2.3. Curiosities

3.4. At the table

\section{GROUP 3. Business etiquette: country's specific characteristics/habits (suggested items)}

3.1. Greetings, introductions and business cards

3.2. Eye-contact, personal space and touch

3.3. Time

3.4. Socialising

3.5. Gift-giving

3.6. Dress and appearance

3.8. Particular cultural attitudes and behaviours

3.9. Tipping customs

3.10. Conversational customs and manners

\section{GROUP 4. Corporate Culture}

4.1. Predominant corporate cultures

4.2. Corporate Social Responsibility: examples of recent initiatives 
Following the invitation to come to an ELBC class and attend students' presentations, a seminar with the ESC volunteers was organised. After discussing the meaning(s), characteristics and different levels of culture, our visitors were also challenged to present their countries and their national cultures to our students, with a special focus too on the implicit manifestations of their culture, such as, for example, their values, attitudes and beliefs, concepts of time and space, authority perception, etc..

The session on December 12 was divided into three moments. Firstly, each group of students was granted 15 minutes to present the results of their research to the class and ESC volunteers. From the presentation of factual data and current trends to the showcase of different musical styles and genres (with particular attention on those that most likely only locals know about), and the screening of a short film where students role-play caricatured figures of Portuguese individuals with some of our most typical behaviours, cultural habits and funny quirks, colloquialism and curious idioms (Fig.3), the end result was a fun yet serious look into ourselves and the matrix - or the "cultural programming of the mind" [25] - we are all built upon.

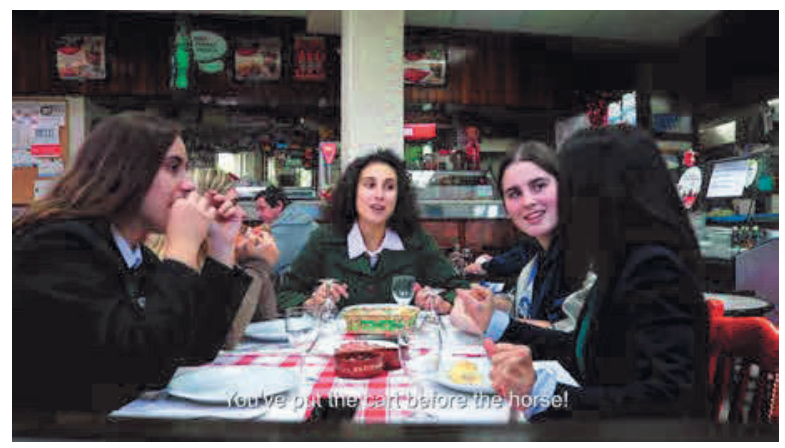

Figure 3. Screenshot of the film "Friends getting together at a Portuguese tavern" (Group 2)

Students' presentations were followed by a coffee break where a variety of traditional confectionery products (proudly) brought by students from their hometowns was served. In a culture where food and gathering around the table are a central part of social relationships and many rituals, this moment was particularly symbolic and meaningful. It also provided students and ESC volunteers with the opportunity to comment on students' presentations and socialize and interact in a more relaxed, informal way.

Afterwards, the floor was given to the ESC volunteers, who participated enthusiastically in the task by introducing their countries to the attendees. Overall, each one of them conducted a candid selfanalysis, which revealed the volunteers' creativity as well as their ability to laugh at themselves and, above all, demonstrated how culture does shape the way we act in our daily lives, see the world and interact with others.

\section{STUDENTS' PERCEPTIONS OF THE ACTIVITIES}

After the end of the semester, students were invited to answer an online questionnaire, which was anonymous and included 16 questions/items that aimed at assessing the overall learning experience as well as the development of specific skills. Answering the questionnaire was not mandatory and data from the 19 participating students was collected.

The questionnaire was divided into three sections: i) the overall learning experience; ii) hard and soft skills development; iii) future initiatives and improvement suggestions (open question). In section I, the response to the first question - Did this activity help you relate the intercultural communication concepts and theories discussed in class with the reality presented by our visitors? - was $100 \%$ positive. As for question number 2 - Which stage(s) of the activity do you consider most interesting and/or rewarding? (Fig. 4) -, to learn about our visitors' cultural background (94.7\%) and the interaction moment $(84.2 \%)$ were the most selected options. $57.9 \%$ of the students also selected the group interaction and the preparation of activity for the event day. The nervousness and unease usually inherent to public speaking, especially in such group age (18/19-year-olds), might have influenced the lower results of the fourth option, the actual presentation. 


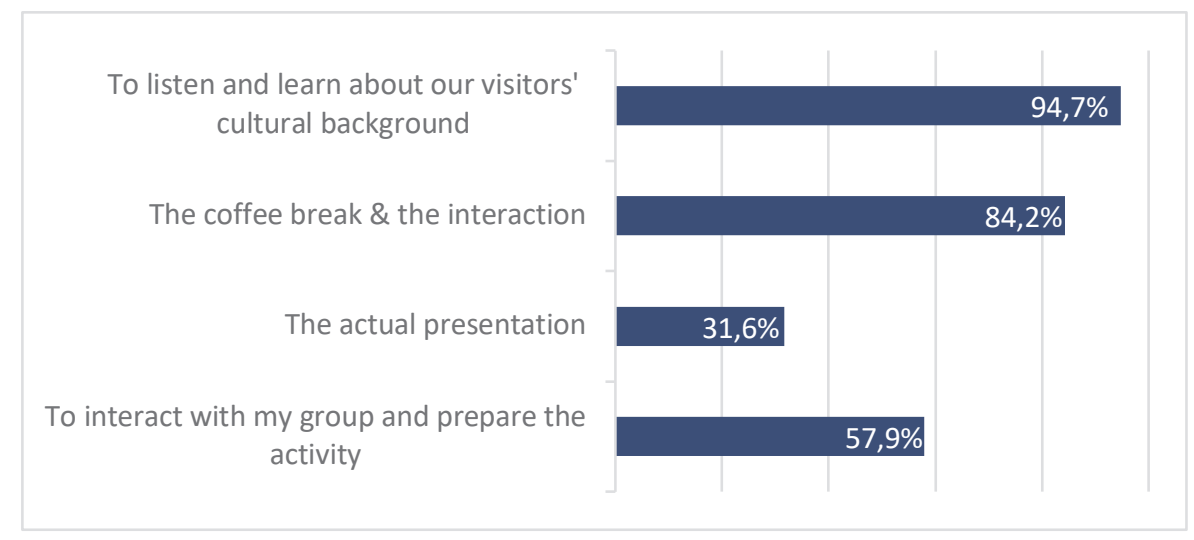

Figure 4. The most interesting and/or rewarding aspect(s) of the activity

As for question 3 - How do you feel about being involved in a formative activity, with no reflection on your final grade? - 17 students considered that, above all, every experience is a learning opportunity, regardless if it's part or not of the formal evaluation. 2 students mentioned that they would have preferred to be formally assessed for their work (even though that's not reason enough to not participate). Regarding the fourth question - On a scale from 1-5, with 1 being 'very bad' and 5 'very good', what's your overall assessment of the activity? - the results are very positive with over twothirds of the students $(78.5 \%)$ considering it a 'very good' experience and the remaining $21.5 \%$ assessing it as a 'good' one.

Section II aimed to assess how this activity contributed to the development of specific skills. A Likertlike scale from 1 to 5 was used for every item and data analysis shows that, on average, students consider the accomplishment of the activity as being very positive. As can be observed in Fig. 5 , skills of a more cognitive and functional nature are assessed with mean values above 4 . According to students' perception, research and information selection skills is the most developed item (4.3) and all other items are assessed with 4.2.

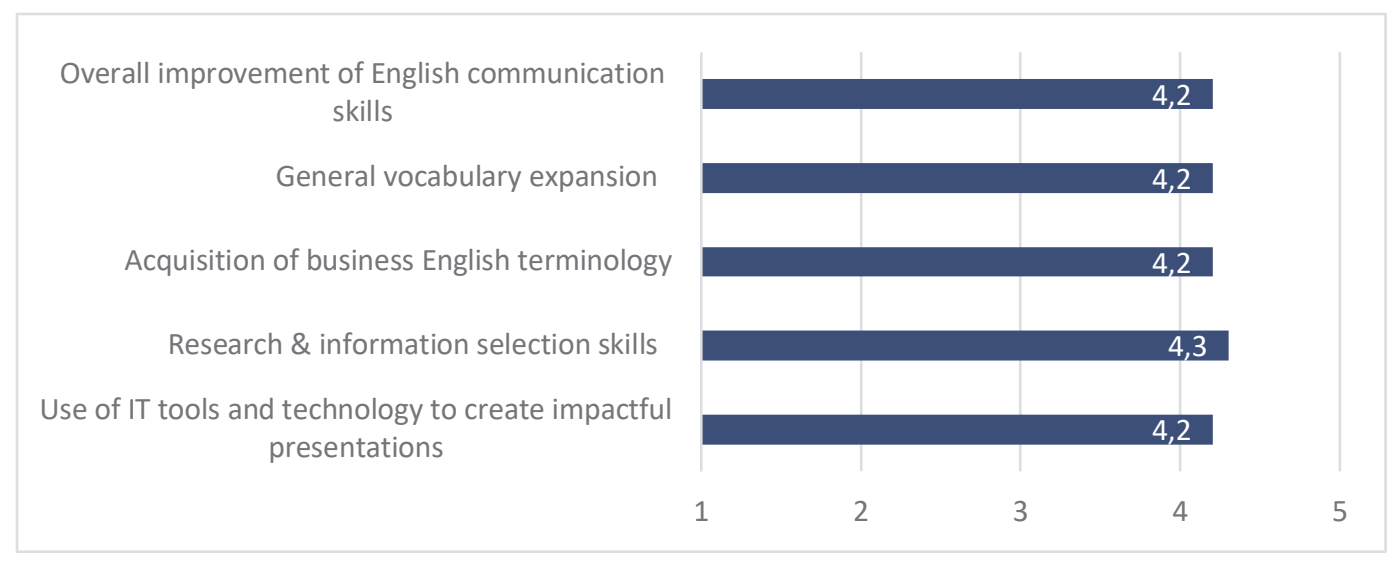

Figure 5. Developed hard skills: students' perception (mean values)

As shown in Table 2, for every assessed item, the value that occurs the highest number of times (mode) is 5.0. General vocabulary expansion (standard deviation 1.1) and Overall improvement of communication skills (standard deviation 1.0) are the items were opinions most diverged, which can be justified with the actual group's heterogeneity in terms of language proficiency level. Nevertheless, the remaining results are quite consistent with all minimum and maximum values between 3.0 and 5.0. 
Table 2: Developed cognitive and functional skills: mean, standard deviation, minimum and maximum, mode and median values

\begin{tabular}{|c|c|c|c|c|c|}
\cline { 2 - 5 } & $\begin{array}{c}\text { Overall } \\
\text { improvement of } \\
\text { English } \\
\text { communication } \\
\text { skills }\end{array}$ & $\begin{array}{c}\text { General } \\
\text { vocabulary } \\
\text { expansion }\end{array}$ & $\begin{array}{c}\text { Acquisition of } \\
\text { business English } \\
\text { terminology }\end{array}$ & $\begin{array}{c}\text { Improvement of } \\
\text { research \& } \\
\text { information } \\
\text { selection skills }\end{array}$ & $\begin{array}{c}\text { Use of IT to } \\
\text { create impactful } \\
\text { presentations }\end{array}$ \\
\hline Mean & 4.2 & 4.2 & 4.2 & 4.3 & 4.2 \\
\hline SD & 1.0 & 1.1 & 0.9 & 0.9 & 0.8 \\
\hline Median & 4.0 & 5.0 & 4.0 & 5.0 & 4.0 \\
\hline Mode & 5.0 & 5.0 & 5.0 & 5.0 & 5.0 \\
\hline Max. & 5.0 & 5.0 & 5.0 & 5.0 & 5.0 \\
\hline Min. & 2.0 & 1.0 & 3.0 & 3.0 & 3.0 \\
\hline \hline
\end{tabular}

Concerning the self-assessment of the developed interpersonal and social competencies, Teamwork (4.7), Creativity (4.6) and Recognition of cultural differences (4.6) received the most positive ratings (Fig. 6). As shown in Table 3, with minimum and maximum values between 4.0 and 5.0 and a standard deviation of 0.5 students' opinions are convergent. With 4.4, the recognition of the impact of cultural differences on global business is another positively developed/consolidated competency, with $63 \%$ of the respondents giving it a score of 5.0 . Similarly to the previous set of competencies, for every assessed soft skill, the mode is also 5.0.

For some students, Autonomy and Time management (with minimum and maximum values between 2.0 and 5.0) seemed more difficult to navigate effectively, which demonstrates that more practical assignments are necessary to more adequately prepare learners for the demands of the current workplace, where not rarely professionals are asked to multitask under tight deadlines.

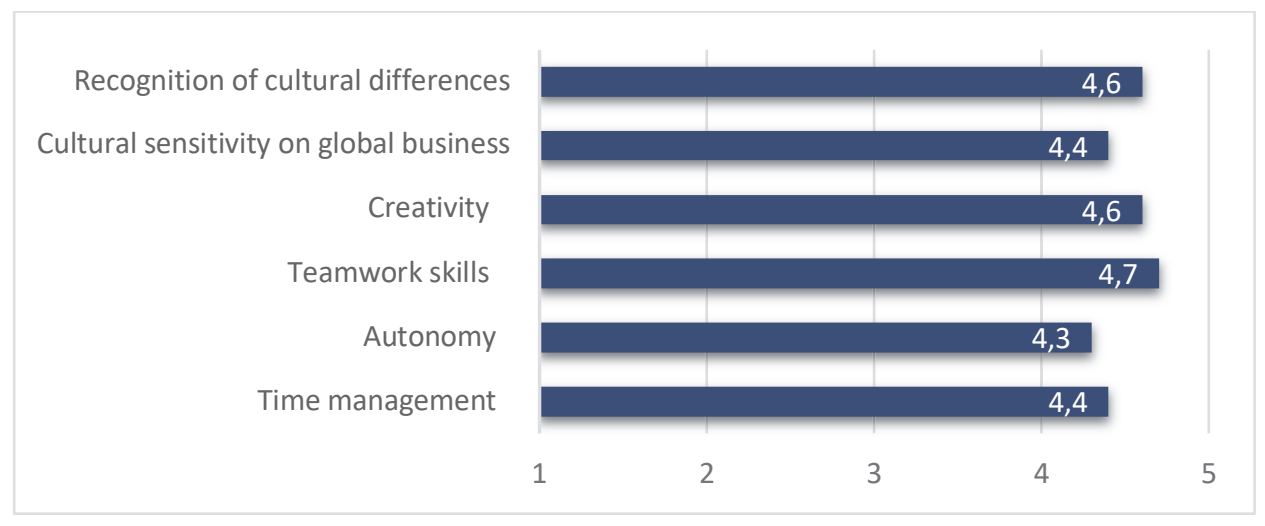

Figure 6. Developed interpersonal and social skills: students' perception (mean values)

Table 3: Interpersonal and social skills: mean, standard deviation, minimum and maximum, mode and median values

\begin{tabular}{|c|c|c|c|c|c|c|}
\cline { 2 - 7 } \multicolumn{1}{c|}{} & $\begin{array}{c}\text { Recognition of } \\
\text { cultural } \\
\text { differences }\end{array}$ & $\begin{array}{c}\text { Cultural } \\
\text { sensitivity on } \\
\text { global business }\end{array}$ & Creativity & $\begin{array}{c}\text { Teamwork } \\
\text { skills }\end{array}$ & Autonomy & $\begin{array}{c}\text { Time } \\
\text { management }\end{array}$ \\
\hline Mean & 4.6 & 4.4 & 4.6 & 4.7 & 4.3 & 4.4 \\
\hline SD & 0.5 & 0.8 & 0.5 & 0.5 & 0.9 & 0.9 \\
\hline Median & 5.0 & 5.0 & 5.0 & 5.0 & 5.0 & 5.0 \\
\hline Mode & 5.0 & 5.0 & 5.0 & 5.0 & 5.0 & 5.0 \\
\hline Max. & 5.0 & 5.0 & 5.0 & 5.0 & 5.0 & 5.0 \\
\hline Min. & 4.0 & 3.0 & 4.0 & 4.0 & 2.0 & 2.0 \\
\hline \hline
\end{tabular}


In the final section of the questionnaire, students were asked to leave a comment and refer to the possibility of repeating the initiative in future editions of the course. The overall opinion is that the initiative had such a positive impact it should again be implemented in the future. Next, a sample of students' final feedback:

"It was an excellent activity that should be repeated next year! It makes us practise everything we learn in English classes, including learning new cultures."

"It is always great to meet new people and learn more about other countries."

"I think it is a good activity for us to interact with people from other cultures, thus learning more about these cultures."

"Close contact with other cultural realities is an excellent way to assimilate knowledge and share experiences in the first person."

"I loved learning a little about other languages and cultures. I think that this experience is very enriching for our professional future."

"These initiatives help a lot to understand how other cultures and countries work and it's interesting to meet people who have completely different perspectives from ours."

\section{CONCLUSIONS}

Considering students' concrete performance in terms of the conducted research, content and materials creation and oral presentations/interactions, as well as their positive feedback on the developed activities, it can be concluded that this student-centred activity was effective, with a beneficial impact in terms of both academic achievement and personal growth.

On the one hand, several course objectives were successfully addressed, namely i) the production of oral and written texts in English; ii) the development of research in the field of intercultural communication; iii) the oral presentation of the results of this research; iv) the production and optimisation of oral and written texts through the use of online/IT tools. On the other hand, the proposed assignment allowed students to develop their intercultural communication skills through teamwork and collaboration, by creating content and present it to an audience, which contributes to the development of a broader set of critical knowledge and competences. Communication and interaction skills, organisation skills, initiative and creativity, assertiveness and problem-solving techniques, or negotiation and conflict resolution skills - all attributes that are highly valued in realworld scenarios - were, on a level or another, developed/consolidated through the presented activity.

By assuming an active rather than passive role in the learning process, such assignments represent an opportunity for students to enter the workforce with experience in the areas of research, team cooperation, even critical thinking and project management, which will constitute a competitive advantage once these graduates enter the labour market.

\section{REFERENCES}

[1] S. Zahidi, "We need a global reskilling revolution - here's why" in World Economic Forum, 22 January 2020. Retrieved from https://www.weforum.org/agenda/2020/01/reskilling-revolution-jobsfuture-skills/.

[2] J. Desjardins, "10 skills you'll need to survive the rise of automation" in World Economic Forum, 2 July 2018. Retrieved from https://www.weforum.org/agenda/2018/07/the-skills-needed-to-survivethe-robot-invasion-of-the-workplace.

[3] M.Y. Brannen, R. Piekkari and S. Tietze, "The Multifaceted Role of Language in International Business: Unpacking the Forms, Functions and Features of a Critical Challenge to MNC Theory and Performance" in Language in International Business (M.Y. Brannen and T. Mughan, eds.), pp. 139-162, London: Palgrave Macmillan, 2017.

[4] J. Landau, Why cultural sensitivity should be a forethought, not an afterthought, Forbes, 17 October 2018. Retrieved from https://www.forbes.com/sites/forbesnycouncil/2018/10/17/whycultural-sensitivity-should-be-a-forethought-not-an-afterthought/\#3d653fb61b69 
[5] R. Jaidev, How pedagogical blogging helps prepare students for intercultural communication in the global workplace. January 2014Language and Intercultural Communication 14(1):132-139, 2014.

[6] T. Portalla and G. Chen. "The development and validation of the intercultural effectiveness scale." Intercultural Communication Studies, vol. 19, no. 3, 2010, pp. 21-37. Available at: https://web.uri.edu/iaics/files/02TamraPortallaGuo-MingChen.pdf

[7] L. Matthews and B. Thakkar, "The Impact of Globalization on Cross-Cultural Communication" in Globalization - Education and Management Agendas, (Ed.) Hector Cuadra-Montiel. IntechOpen, 2012. Retrieved from: https://www.intechopen.com/books/globalization-education-andmanagement-agendas/the-impact-of-globalization-on-cross-cultural-communication

[8] S. Severiens, M. Meeuwisse and M. Born, "Student experience and academic success: comparing a student-centred and a lecture-based course programme", Higher Education, vol. 70, no. 1, pp. 1-17, 2015.

[9] K. Schwab, The Fourth Industrial Revolution: what it means, how to respond. World Economic Forum, 16 January 2016. Retrieved from: https://www.weforum.org/agenda/2016/01/the-fourthindustrial-revolution-what-it-means-and-how-to-respond

[10] K. McLachlan, L. Yeomans, and K.Z.G. Lim, Competency development approach to learning for employment in 3rd International Conference on Higher Education Advances, HEAd'17. Spain: Universitat Politecnica de Valencia, 2017.

[11] European Commission, The European Qualifications Framework for Lifelong Learning (EQF). Luxembourg: Office for Official Publications of the European Communities, 2008.

[12] Indeed, Hard Skills vs. Soft Skills, July 30, 2020. Retrieved from: https://www.indeed.com/careeradvice/resumes-cover-letters/hard-skills-vs-soft-skills

[13] J. Jackson (2015) Preparing students for the global workplace: the impact of a semester abroad, Language and Intercultural Communication, 15:1, 76-91, DOI: 10.1080/14708477.2014.985307

[14] R. Lustig, Can English remain the 'world's favourite' language?, BBC News, 23 May 2018. Retrieved from https://www.bbc.com/news/world-44200901

[15] B. Brock-Utne, "English as the Language of Science and Technology" in Human Rights in Language and STEM Education (Z. Babaci-Wilhite, ed.), pp. 111-128, Rotterdam: Sense Publishers, 2016.

[16] T. Neeley, Global Business Speaks English, Harvard Business Review, May 2012. Retrieved from https://hbr.org/2012/05/global-business-speaks-english\#comment-section

[17] D. K. Deardorff, "Identification and assessment of intercultural competence as a student outcome of internationalization" in Journal of Studies in International Education, vol. 10, No. 3, pp. 241-266, 2006.

[18] G. M., Chen and W.J. Starosta, "Intercultural communication competence: a synthesis", Communication Yearbook, 19, pp. 353-383, 1996.

[19] G. M. Chen, \& W.J. Starosta, "A review of the concept of intercultural sensitivity", Human Communication, 1, pp. 1-16, 1997.

[20] N.V. Yankina, "The role of students' intercultural sensitivity development in a globalized environment," Bulletin of Orenburg State University, issue 2, pp. 178- 183, 2015.

[21] A. B. Hunter, S.L. Laursen and E. Seymour, "Becoming a scientist: The role of undergraduate research in students' cognitive, personal, and professional development", Science Education, no. 91, pp. 36-74, 2007.

[22] D. Lopatto, Science in solution: the impact of undergraduate research on student learning. Tucson: Research Corporation for Science Advancement, 2009.

[23] European Youth Portal (n.d.). "What is the European Solidarity Corps?". Retrieved from https://europa.eu/youth/solidarity_en

[24] E. T. Hall, Beyond Culture, Garden City, New York: Anchor Press, 1976.

[25] G. Hofstede, Cultures, and Organizations: Software of the Mind, 2nd ed. McGraw-Hill: USA, 2005. 